\title{
The demands of an ongoing activity influence the success of event-based prospective memory
}

\author{
RICHARD L. MARSH and THOMAS W. HANCOCK \\ University of Georgia, Athens, Georgia \\ and \\ JASON L. HICKS \\ Louisiana State University, Baton Rouge, Louisiana
}

\begin{abstract}
Four experiments were conducted to evaluate whether event-based prospective memory would be sensitive to the concurrent demands of the ongoing activity in which intention-related cues were embedded. In Experiments 1 and 2, random alternation between two judgments in the ongoing task reduced prospective memory as compared with having a single task throughout. In Experiment 3, participants' making two binary judgments on every trial resulted in worse prospective memory than did their making single four-alternativejudgments. In Experiment 4, participants' making two related judgments resulted in better prospective memory than did their making two unrelated judgments. The results are consistent in spirit with a production rule account of the processing resources that are available when intention-related cues are encountered. Therefore, event-based prospective memory can inversely covary with the cognitive demands of the ongoing activity.
\end{abstract}

When current conditions do not allow the completion of a particular task, people must form intentions to fulfill these activities at some later point in time. Presumably, intentions are stored in memory in a similar fashion as other information that has been recorded there. Memories for intentions have been labeled prospective memories because of their forward-looking nature to a future point at which any necessary conditions to fulfill the task will have been met. One's being able to recognize that the conditions would afford completing the intended activity is often cited as the primary reason for why such memories may be different from standard retrospective memories (e.g., McDaniel \& Einstein, 2000). Those who have followed the burgeoning field of prospective memory will understand that there are many different forms of intentions, and each may have its own unique properties. Therefore, each type of intention potentially has its own set of cognitive processing requirements for successful fulfillment (Brandimonte, Einstein, \& McDaniel, 1996). In the present study, we examined one aspect of what has been labeled eventbased prospectivememory. This type of intention is formed when a person decides to let an environmental cue serve as a reminder that a planned activity should be carried out. For example, a book in front of the door would serve as a good cue to fulfill the intention of returning library books,

We thank Nick Chilivis, Marissa Berland, Jamie Griffin, and Jeracah Holland for their dedicated help in collecting the data. We also thank Elizabeth Maylor, Rob West, and an anonymous reviewer for comments on an earlier draft. Correspondence concerning this article should be addressed to R. L. Marsh, Department of Psychology, University of Georgia, Athens, GA 30602-3013 (e-mail: rlmarsh@uga.edu). or a new flea collar left on a stove burner would be an effective reminder of the intention to replace a pet's collar.

The laboratory analogue to such everyday intentions requires that participants be busily engaged in some ongoing activity. Before starting the ongoing task, they are asked to remember to respond in some fashion whenever a particular target or class of targets appears during the task. Types of ongoing activities that have been used include short-term memory tasks (McDaniel \& Einstein, 1993), sentence verification tasks (Ellis, Kvavilashvili, \& Milne, 1999), word pleasantness rating tasks (Hicks, Marsh, \& Russell, 2000), and famous face identification tasks (Maylor, 1993, 1996), among others. The cues to respond could be particular words (e.g., prefect), a class of items (e.g., words naming animals), or a feature of the stimulus, such as whether a word is a palindrome or whether a face has glasses or a beard. We have labeled this type of procedure the standard Einstein-McDaniel paradigm, after those who originally developed it (e.g., Einstein, Holland, McDaniel, \& Guynn, 1992; Einstein \& McDaniel, 1990; McDaniel \& Einstein, 1993). In the decade since its introduction, this general paradigm has been adapted and modified successfully to answer many important questions about this particular type of memory. However, as the field continues to scrutinize the cognitive processes that subserve event-based memory, we continue to be amazed at just how complex this particular ability really is (Marsh, Hicks, \& Hancock, 2000).

The present study was undertaken to extend a number of recent findings that have demonstrated that event-based memory can be susceptible to the effects of divided attention (e.g., Einstein, McDaniel, Smith, \& Shaw, 1998; Ein- 
stein, Smith, McDaniel, \& Shaw, 1997). Under conditions of divided attention, participants are engaged in the ongoing activity and also have a second task to perform concurrently (e.g., digit detection). In general, divided attention reduces participants' successful responding to prospective cues embedded in the ongoing activity, especially in older adults. In our own work, we have demonstrated that this was particularly true when the concurrent task used to divide attention tapped central executive resources, but no decrement was found when the divided attention task was less resource demanding (Marsh \& Hicks, 1998). Our conclusion has been that event-based memory requires some optimum level of executive resources. By contrast, McDaniel and Einstein (2000) have developed a multiprocess view of prospective memory that delineates some of the factors that would determine whether relatively more automatic versus more controlled cognitive processes are required to fulfill the intention to respond.

On the basis of the notion that event-based memory can require resources, we reasoned that the demands of the ongoing activity in which cues are embedded should influence overall performance. This idea is not new, as Einstein and McDaniel (1996) have made a similar prediction. To our knowledge, other than dividing attention, the task demands of the ongoing activity itself have not been explored systematically (but see Maylor, 1996, p. 77). To do so was the goal of this study. Our own work on divided attention (Hicks \& Marsh, 2000) sensitized us to the claim that any time two tasks must be coordinated, some amount of executive resources are required (Baddeley, 1996). We reasoned that an ongoing activity composed of several subtasks would require these resources, which in turn would diminish the level of resources available for the prospective memory task. We operationalized these predictions in the following manner: If participants had two different types of judgments that had to be made in the ongoing task, their performance at fulfilling the prospective task should decline as compared with participants who had only one type of judgment to make. Although it is correct only to a first approximation, we conceptualized this prediction in terms of Anderson's (1983) ACT* model, which relies heavily on production rules (also see the General Discussion section in Marsh \& Hicks, 1998).

Participants who have only a single activity to perform during the ongoing task need to keep only that one production rule active. For example, one of the tasks used in Experiment 1 was to judge whether the words in the ongoing task contained a long-E sound (e.g., beach). Another task was to decide whether or not an object was living. If participants have only one task to perform throughout the ongoing activity, they should have an optimal level of resources available to respond to the prospective cues. By contrast, if participants must randomly switch between these two types of judgments, they must coordinate two production rules (one pertaining to long-E sounds and another concerning animateness). According to the literature on task switching (e.g., Duncan, 1995), randomly switching between tasks creates task uncertainty, which requires that more attention be paid to the ongoing cognitive processing. In the task switching literature, the costs have primarily been measured in terms of slowed reaction times.

We reasoned from the task switching literature that one's having to load and reload two different production rules unpredictably (i.e., switching randomly between them) from trial to trial would result in task uncertainty and deployment of more attention to the ongoing task. Consequently, worse event-based prospective memory should be found in this condition as compared with the one-judgment condition. This sort of manipulation of the ongoing task is very different from the divided attention studies cited earlier. In those studies, participants were always performing both the ongoing task and the task used to divide attention. In the present experiments, there is no division of attention per se but only a manipulation of the characteristics of the ongoing task itself in terms of the necessity to load and reload different production rules. Although both dividing attention and changing the characteristics of the ongoing task may increase the amount of required resources, both tasks are achieving that same outcome in fundamentally different ways.

\section{EXPERIMENTS 1 AND 2}

Experiments 1 and 2 were highly similar to one another and are reported together for brevity. In both experiments, some participants were tested in a condition in which the ongoing task consisted of a single judgment made on all items. In another condition, the participants were required to make a single judgment for each particular item, but it could be one of two different judgments. In other words, all participants made one judgment per trial, but in the one-judgment condition the same judgment was made consistently, whereas in the two-judgment condition which of the two judgments to make for a given item was switched randomly. If coordinating two different judgments requires resources (e.g., Rogers \& Monsell, 1995), fewer resources should be available in the two-judgment condition. Consequently, prospective memory should be worse in the two-judgment condition, according to our analysis.

\section{Method}

Participants. University of Georgia undergraduates volunteered in exchange for partial credit toward a course requirement. A total of 157 volunteers were tested in Experiments 1 and 2. Assignment of participants to conditions differed slightly in the two experiments. In Experiment 1, a total of 76 people were tested, and half were assigned to the one-judgment condition, and half were assigned to the two-judgment condition ( $n=38$ in each). In the one-judgment condition, half of the participants made long-E judgments (e.g., for the word feat), and half made animateness judgments (e.g., for the word lawyer) throughout ( $n=19$ in each). In Experiment 2, 81 participants were tested. One third were assigned to the two-judgment condition, and one third were assigned to either syllable counting or anagram solving in the one-judgment condition ( $n=27$ in each). Each participant was tested individually in sessions that lasted approximately $25 \mathrm{~min}$.

Materials and Procedure. The procedures used here were virtually identical to those used by Hicks et al. (2000). There were 104 
trials in the ongoing task with a single word presented on each trial. The participants in the one-judgment condition had to make the same, single judgment on all trials. In Experiment 1, this judgment was either a yes-no determination of whether the word contained a long-E sound or whether it represented something living or not. Half of the words should have received a positive response and half should have received a negative one (i.e., the stimulus words for the two dimensions were orthogonally crossed). In Experiment 2, the participants in the one-judgment condition either counted the number of syllables of a word or they inverted two interchanged letters to identify the word presented as an anagram. The interchanged letters were identified with a caret $(\wedge)$ underneath them to make the task slightly easier. In both experiments, the participants assigned to the two-judgment condition had to perform both tasks randomly on different trials of the experiment. To be clear, the participants in the two-judgment condition were making only one judgment per word as the participants were doing in the one-judgment condition. A query appeared on the screen indicating which judgment was to be made, and $0.5 \mathrm{sec}$ later the stimulus appeared. Queries were randomly assigned to trials in each experiment under the constraint that half would receive each type of query. Because queries were used in the two-judgment condition they were also used in the one-judgment condition. Of course, in the latter case, the query never changed from trial to trial (e.g., Long-E? or Syllables?).

Four prospective cues were embedded in the ongoing task at trials $25,50,75$, and 100 . The participants were told that whenever an animal word appeared they should press the " $/$ " key to indicate that they had remembered the intention. We asked that they make their prospective responses after responding to the ongoing task judgment. However, the software recorded a response whenever it was made on any trial, including the 2 -sec intertrial interval. In the twojudgment condition, two prospective cues received each type of judgment. Instructions appropriate to each condition were read from the computer monitor and then verbally reiterated by the experimenter. After the experimenter was convinced that the participants understood the ongoing task, she indicated that we were also interested in their ability to remember to perform an action in the future. After the event-based task was explained, the participants were given a number-finding distractor task for $4 \mathrm{~min}$, after which the ongoing task was commenced without mention of the event-based task.

\section{Results and Discussion}

Unless specified otherwise, statistical significance does not exceed chance by the conventional $5 \%$ throughout this article. Although we have presented Experiments 1 and 2 together, we have treated them as basically separate because they involved different ongoing tasks and because they were conducted at slightly different times. The average proportion of successful prospective responses is summarized in Table 1 along with the average reaction times in the ongoing task on the 100 nonprospective trials. We use these reaction times only to support an ancillary observation about the processing requirements of the ongoing task. In the one-judgment condition of Experiment 1, event-based prospective memory did not depend on the particular judgment being made for the long-E versus animateness task $[t(36)<1.0$, n.s.]. The same was true in Experiment 2, although there was a numerical advantage for what some readers might consider was the shallower processing task of counting syllables versus solving anagrams $[t(52)=1.13$, n.s.]. These null results allowed us to pool over the two types of ongoing tasks in the onejudgment condition and compare them directly with the two-judgment condition. As can be seen in Table 1, prospective memory was worse in the two-judgment condition in which the participants had to randomly switch between different decisions in the ongoing activity. This was true in Experiment $1[t(74)=2.32, S E=0.07]$, but the effect reached conventional significance in Experiment 2 only by a one-tailed test $[t(79)=1.72, S E=0.08]$. Pooling over the two experiments yields a statistically significant difference in event-based performance $[t(155)=2.85$, $S E=0.05]$. Therefore, randomly switching between two judgments versus making one judgment throughout led to the same general outcome in both experiments. Before turning to reaction times, we note that the distributions of prospective memory performance were fairly uniform, insofar as the average performances were not simply a mixture of zero and perfect responders.

One must interpret the degree of processing demands from the reaction time data with caution (e.g., Marsh, Hicks, \& Watson, 2002). Nevertheless, average response time to ongoing task judgments was greater in the two-judgment condition than in the one-judgment condition $[t(74)=6.89$, $S E=143.10$ for Experiment 1 , and $t(79)=3.56, S E=$ 166.02 for Experiment 2]. These results suggest that the participants had more time to process the prospective cues in the two-judgment condition. Despite this extra time that the cue was available to be noticed, prospective memory was worse in the two-judgment condition. Consistent with our hypotheses, these results suggest that the ongoing task demands of coordinating which response had to be made (i.e., task switching) required some processing resources as a consequence of task switching. With less remaining resources to notice and respond to the event-based cues that were embedded in the ongoing activity, performance declined. These outcomes are also consistent with the no-

Table 1

Proportion of Event-Based Prospective Memory Responses and Reaction Times in Experiments 1-4

\begin{tabular}{|c|c|c|c|c|}
\hline \multirow[b]{2}{*}{ Condition } & \multicolumn{2}{|c|}{ Proportion } & \multicolumn{2}{|c|}{ Reaction Time } \\
\hline & Average & $S E M$ & Average & $S E M$ \\
\hline \multicolumn{5}{|c|}{ Experiment 1} \\
\hline Two judgments & .56 & .05 & 2,515 & 124 \\
\hline One judgment & .71 & .04 & 1,529 & 71 \\
\hline Long-E & .70 & .04 & 1,740 & 110 \\
\hline Animateness & .72 & .08 & 1,318 & 60 \\
\hline \multicolumn{5}{|c|}{ Experiment 2} \\
\hline Two judgments & .56 & .08 & 2,478 & 162 \\
\hline One judgment & .71 & .05 & 1,887 & 85 \\
\hline Syllable & .76 & .07 & 1,446 & 61 \\
\hline Anagram & .66 & .06 & 2,328 & 104 \\
\hline \multicolumn{5}{|c|}{ Experiment 3} \\
\hline Combined & .79 & .05 & 3,695 & 122 \\
\hline Discrete & .62 & .04 & 3,733 & 92 \\
\hline Same order & .60 & .05 & 3,524 & 127 \\
\hline Random order & .64 & .06 & 3,942 & 126 \\
\hline \multicolumn{5}{|c|}{ Experiment 4} \\
\hline Unrelated & .52 & .06 & 3,037 & 93 \\
\hline Related & .67 & .06 & 2,406 & 79 \\
\hline
\end{tabular}


tion that a finite amount of processing resources are available (Anderson, 1983; Kahneman, 1973), as well as the general literature on task switching (e.g., Duncan, 1995; Rogers \& Monsell, 1995). When an ongoing activity usurps more resources, there will be fewer available to notice intention-related cues in the environment.

\section{EXPERIMENT 3}

The results of Experiments 1 and 2 suggest that eventbased prospective memory can require processing resources because success inversely covaried with the processing demands of the ongoing task. To a first approximation, we used Anderson's (1983) production rule framework to guide our thinking. In that framework, multiple activities can be compiled into a single production rule and by doing so limited resources should be freed up. Therefore, in this next experiment, we attempted to demonstrate that when two judgments could be compiled into one production rule, event-based memory should be better than when two judgments had to be made independently. In Experiment 3, all participants had to make both of the judgments used in Experiment 1 on each and every word in the ongoing task (i.e., long-E and animateness). In the discrete condition, these two judgments were made serially as two binary judgments. In the combined condition, we fostered compilation of the two judgments into a single production rule by having the participants make a single four-alternative judgment (e.g., animate and long-E, inanimate and long-E, etc.). On the basis of Anderson's framework, we predicted better event-based memory in the combined condition because more resources should be available to notice and to respond to the event-based cues. We also took the opportunity in the discrete condition to manipulate whether the order of the two discrete judgments was random or was the same throughout the ongoing task. One's having to perform two binary judgments in the same order on every trial could facilitate spontaneous compilation of the two judgments into a single production rule like that tested in the combined condition.

\section{Method}

Participants. One hundred fourteen University of Georgia undergraduates volunteered in exchange for partial credit toward a course requirement. Each participant was tested individually in sessions that lasted approximately $25 \mathrm{~min}$. One third of the participants were randomly assigned to the combined condition, and one third were assigned to each of the discrete conditions, in which the two binary judgments were in either the same order or a random order on each trial $(n=38$ in each).

Procedure. The materials and general procedure were identical to those in Experiment 1, except in the following respects concerning the ongoing task. The participants in the discrete condition made two binary judgments on each and every trial of the ongoing task. Half of the participants made their judgments in the same order on each trial of the ongoing task (e.g., animateness followed by long-E or vice versa), and for the other half, the order was entirely random, subject to the constraint that in half of the trials, one order was used and in the other half, the other order was used. A prompt appeared for the first judgment, and after a response was made, a second prompt appeared for the remaining judgment. The participants pressed one of two labeled keys for each judgment, with a total of four different keys being involved. In the combined condition, these same four keys were relabeled to reflect a single judgment with four alternatives: animate and long-E, inanimate and long-E, animate and not long-E, inanimate and not long-E. As in Experiment 1, the stimuli were orthogonally crossed along these two dimensions so that equal numbers of responses should have been issued for each of the four combinations. The prospective memory task was the same (i.e., press the "/" key when an animal word was encountered), and the delay between the prospective instruction and commencement of the ongoing task was $4 \mathrm{~min}$. In all other respects, the experiment conformed to the standard event-based prospective paradigm.

\section{Results and Discussion}

As can be seen in Table 1, identification of the eventbased cues was equivalent for participants tested in the discrete condition regardless of whether the judgments appeared in the same order on all of the trials or whether order was randomly alternated $[t(74)<1.0, S E=0.07$, n.s.]. This outcome suggests that the performing of two discrete judgments that are unrelated to one another, even many times repeatedly, does not appear to cause those two judgments to be compiled into a single task or production rule. The participants took more total time to make their two judgments in the random-order condition than they did in the same-order condition $[t(74)=2.34, S E=$ 178.49]. As in the task switching literature, the cost was on the reaction times and not on the dependent variable of most interest here-namely, prospective memory performance. Our pooling over the two discrete subconditions and comparing them with the combined condition demonstrated better prospective performance with a single fouralternative judgment than with two discrete judgments $[t(112)=2.70, S E=0.06]$. Moreover, this difference in prospective memory was not a consequence of different amounts of total processing time $[t(112)<1.0, S E=$ 156.0, n.s.]. Therefore, this experiment demonstrated that, although two decisions were being made about each item in the ongoing task, when those decisions were compiled into a single production rule, fewer resources were required than to keep two productions active and coordinated (Anderson, 1983). We conclude from these results that when more resources are available in working memory, event-based performance can be benefited (cf. Marsh \& Hicks, 1998).

\section{EXPERIMENT 4}

The final experiment was undertaken to follow up on the finding in Experiment 3 that two discrete judgments, when performed in the same order, did not compile into a single production rule as we had hypothesized might happen. Perhaps we were somewhat naive to believe that two unrelated judgments such as judging words for long-E versus animateness would spontaneously combine into a single judgment; they are, after all, very different judgments. We speculated that if the two discrete judgments were more related to one another, they might sponta- 
neously be combined into a single production without our intervention. If this spontaneous compilation of production rules does occur, it should free up processing resources and improve event-based prospective memory. To test this idea, we had the participants in an unrelated condition make two judgments on each and every trial as they did in the discrete condition of Experiment 3. The judgments were made in a fixed order throughout the ongoing task, and the participants were asked to count the number of letters in the word and then count the number of syllables. In the related condition, the participants counted the number of letters and then made a judgment as to whether there was an odd or even number of letters. We predicted that the two related judgments, despite requiring two discrete responses, would be compiled into a single production rule because the second judgment followed closely on the cognitive processing required for the first judgment. If production rule compilation occurred, more resources would be available in the related condition as compared with the unrelated condition. Consequently, prospective memory should be better in the related condition as compared with the unrelated condition.

\section{Method}

Participants. Seventy-six University of Georgia undergraduates volunteered in exchange for partial credit toward a course research requirement. Each participant was tested individually in sessions that lasted approximately $25 \mathrm{~min}$. Half of the participants were assigned to the related condition, and half were assigned to the unrelated condition ( $n=38$ in each).

Procedure. The general procedure was the same as that used in the previous experiments, except as it concerned the ongoing activity in the two conditions. All participants were required to count the number of letters in the words that appeared. This was the first judgment, and responses were entered by using the number keys across the top row of the keyboard. The participants in the unrelated condition then made a judgment about the number of syllables (stimuli were chosen to ensure a binary response of either 1 or 2 syllables). By contrast, the participants in the related condition made a judgment concerning whether there was an odd or even number of letters. Queries appeared below the words to remind the participants of the two judgments that were required. The prospective memory task was the same as that used in the previous experiments, and the delay between intention formation and commencement of the ongoing task was again $4 \mathrm{~min}$.

\section{Results and Discussion}

As summarized in the last two rows of Table 1, eventbased prospective memory was better in the related condition than in the unrelated condition $[t(74)=1.85, S E=$ $0.08, p=.06]$. On the assumption that the two judgments could be compiled spontaneously into a single production rule in the related condition, this outcome was as predicted. The reaction times on the nonprospective trials indicated that it took longer to make two unrelated judgments than it did to make two related judgments $[t(74)=$ $5.19, S E=121.54]$. Therefore, prospective memory was better in the condition that took less processing time and presumably fewer resources. Despite the fact that the participants had more time available to notice the prospective cue in the unrelated condition, they identified and remembered the intention to respond less frequently. Of course, one criticism of this interpretation would be to argue that the odd/even task is just simpler than syllable counting, and therefore, that compilation has not been demonstrated. However, it is unclear to us on what dimensions judgments of odd/even differ from syllable counting that would account for such a difference in difficulty. This criticism notwithstanding, the results of this experiment complement the results of Experiments 1-3, insofar as they converge on the general message of the study: The demands of the ongoing task can be shown to influence the overall level of event-based prospective memory.

\section{GENERAL DISCUSSION}

We have emphasized the fact that event-based performance can be sensitive to the quantity of resources that are available when a cue is encountered. We attempted to extend the findings that have been reported with divided attention (e.g., McDaniel, Robinson-Riegler, \& Einstein, 1998) to the demands of the ongoing activity itself. We found that when the processing requirements of the ongoing task increased, event-based performance decreased. Therefore, a tradeoff in the processing requirements of the ongoing and prospective tasks can be obtained. When more resources were devoted to the ongoing activity, fewer were available for the prospective task. However, we do wish to go on record as saying that this outcome need not occur with every form of event-based memory. For example, when cues are highly salient, such as when they are presented as uppercase words against a background of lowercase words (e.g., Einstein, McDaniel, Manzi, Cochran, $\&$ Baker, 2000), the demands of the ongoing task are likely to be less important. The same might be true of very well-learned intentions, or in the limit case, of habitual prospective memory tasks (Einstein et al., 1998). Our point is that event-based memory can vary in the amount of controlled processing it might require, and perhaps we have merely tested one form of event-based memory that is sensitive to the demands of the ongoing task.

Recently, we reported that the processing requirements of cue identification and the processing demands of the ongoing task can interact (Marsh et al., 2000). In that study, a semantic intention was fulfilled more often with a semantic ongoing task, and an orthographic intention was fulfilled more often with an orthographic ongoing task, as compared with when the two were mismatched (i.e., the task appropriate processing effect). In that study, we were not concerned with the quantitative amount of resources demanded by the various ongoing tasks. Rather, we were concerned with the qualitative match of the cognitive processing required by both tasks. Those results combined with the present results suggest that both the quantitative and qualitative resources of the ongoing task should influence the success of identifying event-based cues (see also Brunfaut, Vanoverberghe, \& d'Ydewalle, 
2000; West \& Craik, 1999). For example, perhaps the quantitative resources demanded by the ongoing activity matter most when the qualitative processing required to identify the cue differs from that required to perform the ongoing activity. From this standpoint, the quantity of available resources may not matter (or matter less) when taskappropriate processing is present.

To our knowledge, the present study is the first to report that the level of event-based prospective memory will inversely covary with the demands of the ongoing task (apart from the manipulations of divided attention with additional concurrent tasks). In a related vein, we have tried on several occasions to obtain a significant effect of deeper versus shallower processing of event-based cues by manipulating the ongoing task (e.g., Hicks et al., 2000, Experiment 1). However, we have never been successful at finding that shallowly processed cues were responded to less frequently than more deeply processed ones (or vice versa). We speculate that the present results suggest that it may be the overall allocation of attention to the ongoing task (or the experiment as a whole) that matters and not the amount of attention that is manipulated toward individual cues embedded in the ongoing task. In all of the conditions in this study in which event-based memory was worse, the participants should have been allocating more attention to the demands of the ongoing task, and this is especially true when judgments were switched randomly from trial to trial. The idea of overall attentional demands influencing event-based memory is consistent with manipulations of the relative importance of the event-based task (e.g., Kliegel, Martin, McDaniel, \& Einstein, 2001). If the ongoing task is treated by participants as being more important, more resources will be devoted to it and prospective memory will suffer. The converse should also be true. The idea of overall allocation of attention is also consistent with the finding that participants who are given a boring ongoing activity will have better prospective memory than those given an engaging ongoing task (Kvavilashvili, 1992).

We have claimed that event-based memory of the type tested here requires some optimum level of central executive resources (Marsh \& Hicks, 1998). We have no independent evidence from this particular study that the conditions that resulted in worse event-based memory required more executive resources (except for reaction times to the ongoing activity). For this reason, we have not emphasized this claim here. However, our manipulations were chosen based on theory. That theory suggests that the coordination of activities requires executive resources (Baddeley, 1996; Duncan, 1995; Rogers \& Monsell, 1995) and that activation of and compilation of production rules affects similar resources (Anderson, 1983). Consistent with this claim, there is neuropsychological evidence that eventbased retrieval involves the frontal lobes, which have been associated with such resources as well (McDaniel, Glisky, Rubin, Guynn, \& Routhieaux, 1999; West, Herndon, \& Ross-Munroe, 2000). Therefore, we believe that the inde- pendent variable affecting event-based performance is the amount of executive resources, but we acknowledge that some readers might prefer to think of it as general working memory resources until further evidence concerning this issue is obtained. There is currently a debate concerning whether working memory resources correlate positively with event-based prospective memory. Cherry and LeCompte (1999) have argued that a correlation exists, whereas Kidder, Park, Hertzog, and Morrell (1997) have argued that it does not.

Regardless of how one chooses to characterize those resources, the implications of the present study for everyday prospective memory are straightforward. When engrossed in a task, lost in thought, or otherwise deeply preoccupied, cues in the environment that are related to previously established intentions are less likely to be noticed. Therefore, as with many other cognitive tasks, event-based prospective memory can be subject to dual-task performance tradeoffs. In some cases, the saliency of the cue or the strength of the association between the cue and the intention may be able to counteract the deleterious effects of fewer processing resources. However, it remains to be seen just how resilient event-based memory can be in the context of fewer processing resources and the qualitative type of demands placed on the cognitive system when an intention-related cue is encountered.

\section{REFERENCES}

Anderson, J. R. (1983). The architecture of cognition. Cambridge, MA: Harvard University Press.

BADDELEY, A. (1996). Exploring the central executive. Quarterly Journal of Experimental Psychology, 49A, 5-28.

Brandimonte, M., Einstein, G. O., \& McDaniel, M. A. (1996). Prospective memory: Theory and applications. Hillsdale, NJ: Erlbaum. Brunfaut, E, Vanoverberghe, V., \& D’Ydewalle, G. (2000). Prospective remembering of Korsakoffs and alcoholics as a function of the prospective-memory and on-going tasks. Neuropsychologia, 38, 975984.

Cherry, K. E., \& LeCompte, D. C. (1999). Age and individual differences influence prospective memory. Psychology \& Aging, 14, 60-76.

Duncan, J. (1995). Attention, intelligence, and the frontal lobes. In M. S. Gazzaniga (Ed.), The cognitive neurosciences (pp. 721-733). Cambridge, MA: MIT Press.

Einstein, G. O., Holland, L. J., McDaniel, M. A., \& Guynn, M. J. (1992). Age-related deficits in prospective memory: The influence of task complexity. Psychology \& Aging, 7, 471-478.

Einstein, G. O., \& MCDANiEL, M. A. (1990). Normal aging and prospective memory. Journal of Experimental Psychology: Learning, Memory, \& Cognition, 16, 717-726.

Einstein, G. O., \& McDAniel, M. A. (1996). Retrieval processes in prospective memory: Theoretical approaches and some new empirical findings. In M. Brandimonte, G. O. Einstein, \& M. A. McDaniel (Eds.), Prospective memory: Theory and applications (pp. 115-141). Hillsdale, NJ: Erlbaum.

Einstein, G. O., McDaniel, M. A., Manzi, M., Cochran, B., \& BAKER, M. (2000). Prospective memory and aging: Forgetting intentions over short delays. Psychology \& Aging, 15, 671-683.

Einstein, G. O., McDaniel, M. A., Smith, R. E., \& Shaw, P. (1998). Habitual prospective memory and aging: Remembering intentions and forgetting actions. Psychological Science, 9, 284-289.

Einstein, G. O., Smith, R. E., McDaniel, M. A., \& Shaw, P. (1997). Aging and prospective memory: The influence of increased task demands at encoding and retrieval. Psychology \& Aging, 12, 479-488. 
Ellis, J., Kvavilashvili, L., \& Milne, A. (1999). Experimental tests of prospective remembering: The influence of cue-event frequency on performance. British Journal of Psychology, 90, 9-23.

Hicks, J. L., \& MArsh, R. L. (2000). Toward specifying the attentional demands of recognition memory. Journal of Experimental Psychology: Learning, Memory, \& Cognition, 26, 1483-1498.

Hicks, J. L., Marsh, R. L., \& Russell, E. J. (2000). The properties of retention intervals and their affect on retaining prospective memories. Journal of Experimental Psychology: Learning, Memory, \& Cognition, 26, 1160-1169.

Kahneman, D. (1973). Attention and effort. Englewood Cliffs, NJ: Prentice-Hall.

Kidder, D. P., Park, D. C., Hertzog, C., \& Morrell, R. W. (1997). Prospective memory and aging: The effects of working memory and prospective memory task load. Aging, Neuropsychology, \& Cognition, 4, 93-112.

Kliegel, M., Martin, M., McDaniel, M. A., \& Einstein, G. O. (2001). Varying the importance of a prospective memory task: Differential effects across time- and event-based prospective memory. Memory, 9, 1-11.

KvavilashVILI,L. (1992). Remembering intentions: A critical review of existing experimental paradigms. Applied Cognitive Psychology, 6, 507-524.

Marsh, R. L., \& Hicks, J. L. (1998). Event-based prospective memory and executive control of working memory. Journal of Experimental Psychology: Learning, Memory, \& Cognition, 24, 336-349.

Marsh, R. L., Hicks, J. L., \& Hancock, T. W. (2000). On the interaction of ongoing cognitive activity and the nature of an event-based intention. Applied Cognitive Psychology, 14, S29-S42.

Marsh, R. L., Hicks, J. L., \& Watson, V. (2002). The dynamics of intention retrieval and coordination of action in event-based prospective memory. Journal of Experimental Psychology: Learning, Memory, \& Cognition, 28, 652-659.

MAYLOR, E. A. (1993). Aging and forgetting in prospective and retrospective memory tasks. Psychology \& Aging, 8, 420-428.

MAYLOR, E. A. (1996). Age-related impairment in an event-based prospective memory task. Psychology \& Aging, 11, 74-79.

McDaniel, M. A., \& Einstein, G. O. (1993). The importance of cue familiarity and cue distinctiveness in prospective memory. Memory, $\mathbf{1}$, 23-41.

McDaniel, M. A., \& Einstein, G. O. (2000). Strategic and automatic processes in prospective memory retrieval: A multiprocess framework. Applied Cognitive Psychology, 14, S127-S144.

McDaniel, M. A., Glisky, E. L., Rubin, S. R., Guynn, M. J., \& Routhieaux, B. C. (1999). Prospective memory: A neuropsychological study. Neuropsychology, 13, 103-110.

McDaniel, M. A., Robinson-Riegler, B., \& Einstein, G. O. (1998). Prospective remembering: Perceptually driven or conceptually driven processes? Memory \& Cognition, 26, 121-134.

Rogers, R. D., \& Monsell, S. (1995). Costs of a predictable switch between simple cognitive tasks. Journal of Experimental Psychology: General, 124, 207-231.

WeSt, R. L., \& CRAIK, F. I. M. (1999). Effects of aging, cover task demands, immediacy of response, and cue characteristics on event-based prospective memory. Brain \& Cognition, 39, 25-28.

West, R. L., Herndon, R. W., \& Ross-Munroe, K. (2000). Event-related neural activity associated with prospective remembering. Applied Cognitive Psychology, 14, S115-S126.

(Manuscript received February 6, 2001; revision accepted for publication September 12, 2001.) 